\title{
Determinação da lâmina ótima de água para cultura do milho doce na região de Sete Lagoas, MG
}

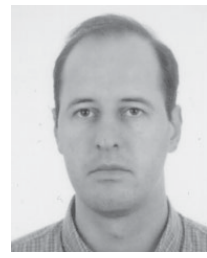

\author{
Alexandre B. Heinemann', Sérgio A.V. de Sousa² \& José A. Frizzone ${ }^{3}$ \\ 1 COPERSUCAR, C.P. 9, CEP 13418-900, Piracicaba, SP. Fone: (19) 429-4217. E-mail: abheinem@carpa.ciagri.usp.br (Foto) \\ 2 ESALQ/USP. C.P. 162, CEP 13400-970, Piracicaba, SP. Fone: (19) 429-8191. E-mail: savsousa@copersucar.com.br \\ ${ }^{3}$ ESALQ/USP. Departamento de Engenharia Rural/Irrigação. E-mail: frizzone@carpa.ciagri.usp.br
}

Protocolo $133-27 / 10 / 2000$

\begin{abstract}
Resumo: Com este trabalho, propõe-se determinar a lâmina de água que resulta na maior receita líquida para a cultura do milho doce (Zea mays, L.) na região de Sete Lagoas, MG, no período de dezembro a fevereiro (época das chuvas) utilizando-se análise de decisão. Quatro lâminas de irrigação (385, 289, 193 e $96 \mathrm{~mm}$ ) foram utilizadas. A lâmina de $385 \mathrm{~mm}$ é a que fornece a máxima produtividade física, obtida através de uma função de produção. Os resultados indicaram, pela análise de sensibilidade que, para o preço da unidade de água até $R \$ 0,36$ para cada $10 \mathrm{~m}^{3}$, a lâmina de irrigação de $385 \mathrm{~mm}$ apresentou a maior receita líquida. Para um preço da unidade de água maior que $\mathrm{R} \$ 0,36$ para cada $10 \mathrm{~m}^{3}$, a lâmina correspondente a $75 \%$ da lâmina máxima (289 $\mathrm{mm}$ ) proporcionou a maior receita líquida.
\end{abstract}

Palavras-chave: análise de decisão, simulação, milho doce, Zea mays

\section{Determination of the optimal irrigation depth for sweet corn in Sete Lagoas, MG}

\begin{abstract}
The objective of this study was to determine the optimal irrigation application that gives the maximum revenue of sweet corn during the rainy season, in Sete Lagoas, State of Minas Gerais, Brazil. Decision criterion was used to determine the optimal irrigation application. Four irrigation depths were used $(385,289,193$ and $96 \mathrm{~mm})$. The irrigation water amount of $385 \mathrm{~mm}$ was calculated from a production function and this water amount gave the maximum yield. The results showed that the $385 \mathrm{~mm}$ gave the best revenue, considering the water price up to $\mathrm{R} \$ 0.36$ per $10 \mathrm{~m}^{3}$. With a higher water price, the best revenue was obtained when the irrigation water depth was $289 \mathrm{~mm}$.
\end{abstract}

Key words: decision analysis, simulation, sweet corn, Zea mays

\section{INTRODUÇÃO}

Na cultura do milho, a disponibilidade de água passa a ser fator decisivo no potencial de produção e rendimento, no período compreendido entre os $3^{\circ}$ e $5^{\circ}$ estádios, ou seja, com 85 a $90 \%$ da área foliar e florescimento até o estádio de enchimento dos grãos (Fancelli \& Dourado Neto, 1996).

Normalmente, a quantidade total de água necessária para a irrigação é calculada levando-se em consideração fatores agrometeorológicos, evapotranspiração real, capacidade de armazenamento de água do solo e profundidade efetiva do sistema radicular (Bernardo, 1989; Klar, 1991; Marouelli et al., 1994). Existem, também, diversos trabalhos que determinaram a lâmina total de irrigação para obter a maior produtividade física destacando-se, dentre eles, Silva et al. (1992) e Couto et al. (1986) que avaliaram os efeitos do estresse hídrico no rendimento de grãos de milho. Silva et al. (1992) trabalharam com cinco níveis diferentes de lâmina de água, sendo que as lâminas totais (precipitação + lâmina média aplicada) variaram entre 109 até $753 \mathrm{~mm}$, para o ciclo total da cultura, obtendo-se rendimentos variando entre $1.638,3$ até $8.543,2 \mathrm{~kg} \mathrm{ha}^{-1}$. No trabalho de Couto et al. (1986) apesar da alta precipitação durante a fase experimental $(974 \mathrm{~mm}$ ) sua distribuição foi irregular, causando estresse hídrico nas fases de polinização e enchimento dos grãos. Com a aplicação de apenas $42 \mathrm{~mm}$, distribuídos durante o ciclo da cultura, ocorreu acréscimo de $44,3 \%$ no rendimento dos grãos. No tratamento que recebeu uma lâmina total de água de irrigação de $104 \mathrm{~mm}$, distribuídos durante todo o ciclo da cultura, o acréscimo no rendimento dos grãos foi de 93,7\%.

O déficit hídrico ocorre quando se estabelece um programa de irrigação em que a lâmina média aplicada seja menor que a lâmina média evapotranspirada. Esse manejo é mais eficiente em sistemas de irrigação, que permitem a aplicação de irrigações mais freqüentes (menor turno de rega) e com menor lâmina, como é o caso de irrigação por gotejamento, microaspersão, autopropelido e pivô central (Bernardo, 1989). Segundo English 
et al. (1990) pode-se obter aumento na receita líquida quando o volume de água disponível é limitante à produção e a água economizada pela aplicação de uma lâmina de irrigação, que proporciona déficit hídrico na cultura, pode ser utilizada no aumento da área irrigada.

Sousa et al. (1996) utilizando programação linear, estudaram a lâmina ótima de irrigação para diferentes déficits hídricos nas culturas de feijão, milho, melancia e tomate. Os autores verificaram que, quando a água economizada pelo déficit hídrico aplicado pôde ser utilizada para aumento da área irrigada, a maior receita líquida foi obtida com a aplicação de um déficit hídrico de $20 \%$; caso contrário, a maior receita líquida foi obtida para um déficit hídrico de $10 \%$ nas quatro culturas.

Em termos econômicos, a implantação e a operação de sistemas de irrigação envolvem custos elevados e, normalmente, a máxima produtividade física não corresponde à maior receita líquida, devido a natureza complexa da resposta das culturas à irrigação, variabilidade climática e flutuações das condições econômicas (Algozin et al., 1988); logo, para uma empresa agrícola a determinação de aplicação de uma lâmina de água de irrigação que proporcione a maior receita líquida, torna-se importante.

Uma maneira de se escolher uma lâmina de água economicamente viável entre diferentes opções de lâminas de água existentes, é a utilização de técnicas que auxiliem na tomada de decisão. Para a realização deste trabalho, utilizou-se o método de decisão denominado "árvore de decisão", o qual permite a colocação de uma extensa gama de conceitos e técnicas que auxiliem na tomada de decisão, em condições de incerteza, de problemas complexos (Moskowitz, 1986) fornecendo uma metodologia racional para a tomada de decisão, em face da incerteza. A análise de decisão denominada "árvore de decisão" é dividida em quatro fases distintas: decisão do produtor; alternativa dos cursos de ação; eventos e conseqüências.

Este trabalho tem como objetivo determinar a lâmina de água, para fornecer a maior receita líquida para a cultura do milho doce, na região de Sete Lagoas, $\mathrm{MG}$, e analisar o efeito da variação do preço da unidade de água e do preço do produto na receita líquida.

\section{MATERIAL E MÉTODOS}

Para a realização deste trabalho considerou-se que a cultura do milho doce possui um período médio entre a emergência das plantas e a colheita, de aproximadamente 90 dias. O plantio foi realizado em dezembro, ocorrendo o período de florescimento no mês de janeiro e o de enchimento de grãos no mês de fevereiro.

Para a decisão do produtor, foram empregadas quatro diferentes alternativas de cursos de ação: lâmina total correspondente ao máximo rendimento físico (Opção 1), lâmina total 25 \% (Opção 2), 50\% (Opção 3), 75\% (Opção 4) menor que a lâmina correspondente ao máximo rendimento físico.

Através da função de produção determinada por Oliveira (1993) em Sete Lagoas, MG, calcularam-se as opções 1, 2, 3 e 4.

$$
\mathrm{Y}=-10472,43+112,10 \mathrm{~W}-0,1438 \mathrm{~W}^{2}
$$

em que:

$\mathrm{Y}$ - rendimento do milho doce, $\mathrm{kg}$

W - lâmina total de água aplicada, mm
A lâmina máxima obtida pela derivação da Eq. 1 foi de 385 mm e as lâminas utilizadas nas opções 2, 3 e 4 foram de 289, 193 e $96 \mathrm{~mm}$, respectivamente.

Neste trabalho houve possibilidade de ocorrência de dois tipos de evento, ótimo e não-ótimo, que representaram as probabilidades de ocorrência de redução ou não do rendimento de grãos de milho doce, sendo evento ótimo aquele em que não ocorreu redução no rendimento dos grãos, nos meses de janeiro e fevereiro, e evento não-ótimo quando houve redução no rendimento, nos respectivos meses. $\mathrm{O}$ evento não-ótimo foi subdividido em cinco partes representando, para cada mês, a ocorrência de uma redução do rendimento de até $10 \%$, entre 10 e $20 \%$, entre 20 e $30 \%$, entre 30 e $40 \%$ e maior que $40 \%$. O evento ótimo foi definido como a probabilidade de não ocorrer perda no rendimento.

A probabilidade das quebras de produção foi calculada utilizando-se o programa "Veranico" (Sousa \& Peres, 1996). A redução no rendimento foi obtida relacionando-se o déficit de evapotranspiração simulado com os coeficientes de resposta à água (Ky) proposta por Doorenbos \& Kassam (1979). Os dados necessários para as simulações no programa "Veranico" são: as seqüências observadas, de dias consecutivos sem chuva; a evapotranspiração de referência $\left(\mathrm{ET}_{0}\right)$; os valores de coeficientes de cultivo (Kc) e os dados de solo (umidade na capacidade de campo, no ponto de murcha permanente, e a profundidade do sistema radicular). Para este trabalho, a seqüência de dias consecutivos sem chuva foi determinada considerando-se dia seco aquele em que a precipitação diária foi menor ou igual a $\mathrm{ET}_{0}$ média em base diária para o mês em questão. No cálculo da $\mathrm{ET}_{0}$ utilizou-se o modelo proposto por Priestley \& Taylor (1972). Utilizaram-se os valores de Kc propostos por Doorenbos \& Pruitt (1977) e os dados de solo foram obtidos no trabalho de Oliveira (1993). Para a Opção 1, nos meses de janeiro e fevereiro, a ocorrência do evento não-ótimo foi nula pois, através do equipamento de irrigação, aplicou-se a lâmina total de água, distribuída pelo ciclo da cultura, que proporcionou o máximo rendimento físico da cultura, não dependendo de ocorrência de precipitação pluvial.

Para as Opções 2, 3 e 4, nos meses de janeiro e fevereiro, foi simulada a ocorrência do evento não-ótimo, pois nesta situação foi aplicada uma lâmina de água menor que a lâmina total, que proporciona o máximo rendimento físico.

Os valores da probabilidade de ocorrência dos eventos simulados ótimo e não-ótimo, são apresentados na Tabela 1. Apesar da pressuposição inicial de ocorrência de redução do rendimento de grãos superiores a $40 \%$, para o mês de fevereiro, essas reduções não ocorreram devido à alta probabilidade de ocorrência de chuvas nesse mês. As maiores reduções de rendimento simuladas para o maior veranico no mês, foram inferiores a $40 \%$.

Os rendimentos da cultura do milho doce, para as diferentes lâminas, foram calculados pela Eq. 1. Para cada opção e percentagem de redução de rendimento (evento "não-ótimo") os valores dos rendimentos líquidos foram obtidos pela soma do rendimento correspondente a cada lâmina, de cada opção, com o rendimento obtido pela diferença entre o máximo rendimento e o rendimento correspondente à lâmina aplicada.

$$
\mathrm{Y}_{\text {liq }}=\mathrm{Y}_{\mathrm{fw}}+(1-\% \text { quebra })\left(\mathrm{Y}_{\text {máx }}-\mathrm{Y}_{\mathrm{fw}}\right)
$$


Tabela 1. Freqüências de ocorrência de cada evento, para os meses de janeiro e fevereiro

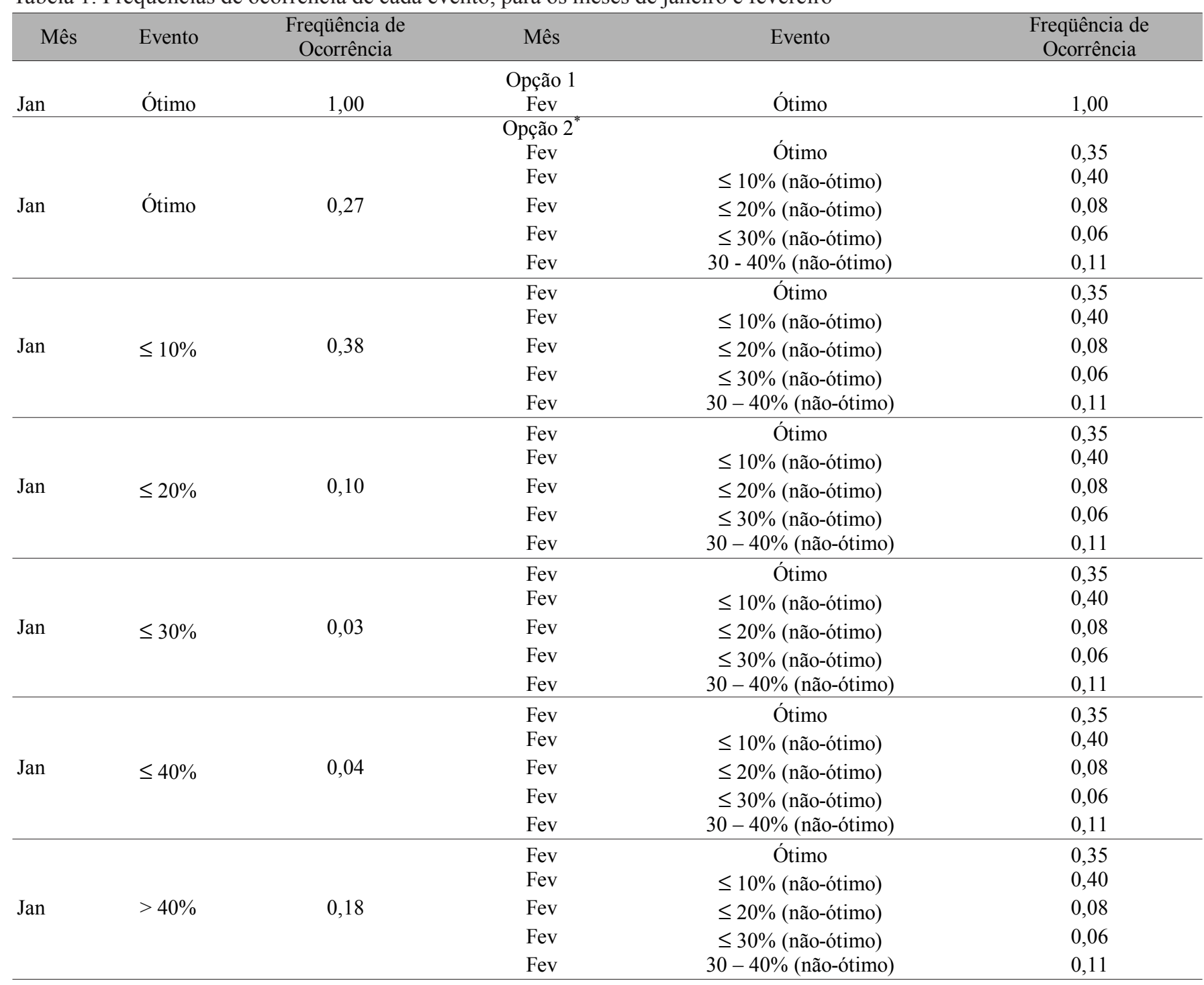

*As freqüências de ocorrência dos eventos para as opções 3 e 4 são as mesmas apresentadas para a opção 2

em que:

$\mathrm{Y}_{\text {liq }}$ - rendimento líquido do milho doce, $\mathrm{kg} \mathrm{ha}^{-1}$

$\mathrm{Y}_{\mathrm{fiv}}$ - rendimento em função da lâmina de água aplicada, $\mathrm{kg} \mathrm{ha}^{-1}$

$\mathrm{Y}_{\text {máx }}$ - rendimento para a máxima lâmina de água, $\mathrm{kg} \mathrm{ha}^{-1}$

Como exemplo de cálculo foi considerada a Opção 2, na qual a lâmina total de água de irrigação aplicada foi de $289 \mathrm{~mm}$ e o rendimento em função desta lâmina $\left(\mathrm{Y}_{\mathrm{fw}}\right)$ foi de $9.451,66 \mathrm{~kg} \mathrm{ha}^{-1}$. Considerando-se a ocorrência do evento ótimo para o mês de janeiro (sem redução do rendimento) e uma redução no rendimento para o mês de fevereiro de $10 \%$, obteve-se uma produção mínima garantida de $9.451,66 \mathrm{~kg} \mathrm{ha}^{-1}$, já que a mesma vinha da irrigação; assim, a redução de $10 \%$ no rendimento ocorreu na diferença entre o rendimento relativo à lâmina máxima $\left(\mathrm{Y}_{\operatorname{máx}}=10.755,12 \mathrm{~kg} \mathrm{ha}^{-1}\right) \mathrm{e}$ o rendimento referente à lâmina de água aplicada $\left(\mathrm{Y}_{\mathrm{fw}}=9.451,66 \mathrm{~kg} \mathrm{ha}^{-1}\right)$; neste caso, a redução no rendimento foi de $130,35 \mathrm{~kg} \mathrm{ha}^{-1}$, sendo o rendimento líquido de $10.624,77 \mathrm{~kg} \mathrm{ha}^{-1}$. Este procedimento foi feito para cada condição de lâmina e percentagem de redução no rendimento, obtendo-se os rendimentos líquidos para cada situação.
Quando ocorreu o evento não-ótimo, em janeiro e fevereiro, o rendimento líquido final foi determinado aplicando-se duas vezes a Eq. 2, considerando-se as respectivas lâminas e percentagens de redução de rendimento de cada situação, sendo considerado, na segunda vez, como valor de rendimento máximo, o rendimento líquido obtido no primeiro cálculo.

A receita líquida em cada opção foi calculada pela seguinte equação:

$$
\mathrm{RL}=\mathrm{Y}_{\text {liq. }} \mathrm{P}_{\mathrm{p}}-\left(\mathrm{C}_{\mathrm{p}}+\mathrm{C}_{\mathrm{s}}+\mathrm{C}_{\mathrm{w}} \mathrm{W}\right)
$$

em que:

$\mathrm{RL} \quad$ - receita líquida da cultura do milho doce, $\mathrm{R} \$ \mathrm{ha}^{-1}$

$\mathrm{Y}_{\text {liq }}$ - rendimento líquido da cultura do milho doce, $\mathrm{kg} \mathrm{ha}^{-1}$

$\mathrm{P}_{\mathrm{P}} \quad$ - preço do produto, $\mathrm{R} \$ \mathrm{~kg}^{-1}$

$\mathrm{C}_{\mathrm{p}}$ - custo de produção, exceto o custo da irrigação, $\mathrm{R} \$ \mathrm{ha}^{-1}$

$\mathrm{C}_{\mathrm{s}}^{\mathrm{p}}$ - custo anual de implantação do sistema de irrigação, $\mathrm{R} \$ \mathrm{ha}^{-1}$

$\mathrm{C}_{\mathrm{w}}$ - preço da unidade de lâmina total média de água, $\mathrm{R} \$ \mathrm{~m}^{-3}$ $\left(\mathrm{C}_{\mathrm{s}}+\mathrm{C}_{\mathrm{w}} \cdot \mathrm{W}\right)$ - custo da irrigação, $\mathrm{R} \$ \mathrm{ha}^{-1}$

W - lâmina total de água aplicada em cada opção, mm 
Tabela 2. Valores de $\mathrm{P}_{\mathrm{p}}, \mathrm{C}_{\mathrm{p}}, \mathrm{C}_{\mathrm{s}}, \mathrm{C}_{\mathrm{w}} \mathrm{e} \mathrm{W}$ para as quatro opções de irrigação

\begin{tabular}{|c|c|c|c|c|c|}
\hline Opções & $\begin{array}{c}\mathrm{P}_{\mathrm{p}} \\
\left(\mathrm{R} \$ \mathrm{~kg}^{-1}\right)\end{array}$ & $\begin{array}{c}\mathrm{C}_{\mathrm{p}} \\
\left(\mathrm{R} \$ \mathrm{ha}^{-1}\right)\end{array}$ & $\begin{array}{c}\mathrm{C}_{\mathrm{S}} \\
\left(\mathrm{R} \$ \mathrm{ha}^{-1} \mathrm{ano}^{-1}\right)\end{array}$ & $\begin{array}{c}\mathrm{C}_{\mathrm{w}} \\
\left(\mathrm{R} \$ 10 \mathrm{~m}^{-3}\right)\end{array}$ & $\begin{array}{c}\mathrm{W} \\
(\mathrm{mm})\end{array}$ \\
\hline 1 & 0,171 & 624,17 & 208,60 & 0,15 & 385 \\
\hline 2 & 0,171 & 624,17 & 166,40 & 0,15 & 289 \\
\hline 3 & 0,171 & 624,17 & 122,70 & 0,15 & 193 \\
\hline 4 & 0,171 & 624,17 & 76,70 & 0,15 & 96 \\
\hline
\end{tabular}

Na Tabela 2 são apresentados os valores de $\mathrm{P}_{\mathrm{p}}, \mathrm{C}_{\mathrm{p}}, \mathrm{C}_{\mathrm{s}}, \mathrm{C}_{\mathrm{w}} \mathrm{e}$ W, utilizados no trabalho.

Os valores do preço do produto $\left(\mathrm{P}_{\mathrm{p}}\right)$ e do custo de produção sem o custo da irrigação $\left(\mathrm{C}_{\mathrm{p}}\right)$ foram obtidos no trabalho de Nehmi et al. (1996); já o custo anual de implantação do sistema de irrigação $\left(\mathrm{C}_{\mathrm{s}}\right)$ para cada lâmina, foi determinado por meio de uma planilha eletrônica desenvolvida com base na metodologia apresentada por Zocoler (1994).

O custo da unidade de água foi obtido no trabalho de Dantas Neto (1994) para o Projeto de Irrigação Senador Nilo Coelho, em Petrolina, PE, e continuou considerado o mesmo, por não haver dados disponíveis para a região de Sete Lagoas, enquanto as análises de sensibilidade realizadas permitiram que se verificasse a influência de possíveis variações desse custo na receita líquida.

Com os valores das probabilidades simuladas para cada evento, bem como dos rendimentos e das receitas líquidas calculadas para cada opção e percentagem de redução de rendimento dos grãos, montou-se a árvore de decisão esquematizada na Figura 1, na qual as opções 2 e 3 apresentam os mesmos ramos da opção 4 para janeiro e, para cada ramo de janeiro, estão presentes os mesmos ramos de fevereiro.

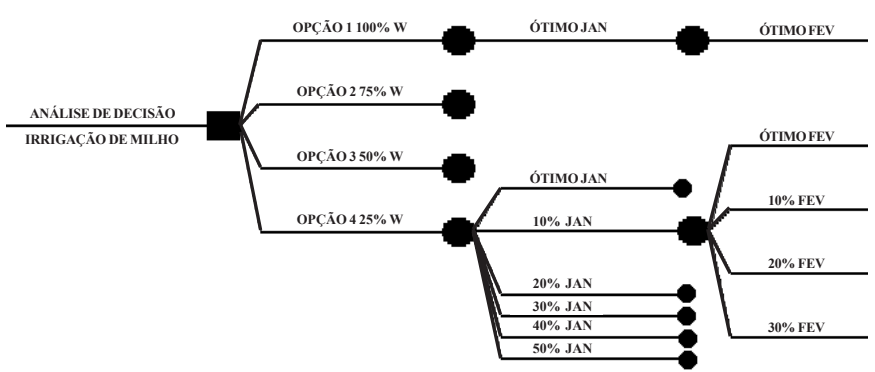

Figura 1. Esquema representativo da árvore de decisão para seleção da lâmina de irrigação, em que W representa a lâmina total de água de irrigação que proporciona o máximo rendimento físico (385 mm), JAN é o mês de janeiro e FEV é o mês de fevereiro

\section{RESULTADOS E DISCUSSÃO}

Na Tabela 3 tem-se o resumo dos resultados obtidos para a receita líquida e a percentagem do custo total da irrigação na receita líquida obtida para as opções 1 (385 mm), 2 (289 mm), 3 (193 mm) e 4 (96 mm).

Analisando-se a Tabela 3, observa-se que a lâmina correspondente ao máximo rendimento físico (opção 1) apresentou a maior receita líquida, relativo ao valor de $\mathrm{R} \$ 948,62 \mathrm{ha}^{-1}$. Esses resultados diferem dos obtidos por Sousa et al. (1996) sendo que esta diferença nos resultados pode ser explicada pelas condições climáticas da região, nas quais as probabilidades de perda decorrentes de veranicos, são consideráveis (Tabela 1) e, também, devido ao baixo custo da unidade de água, o que torna
Tabela 3. Receita líquida e a percentagem do custo da irrigação

\begin{tabular}{ccc} 
Opções & $\begin{array}{c}\text { Receita Líquida } \\
\left(\mathrm{R} \$ \text { ha }^{-1}\right)\end{array}$ & $\begin{array}{c}\text { \% do Custo } \\
\text { da Irrigação }\end{array}$ \\
\hline $1(385 \mathrm{~mm})$ & 948,62 & $28,08 \%$ \\
$2(289 \mathrm{~mm})$ & 928,06 & $22,60 \%$ \\
$3(193 \mathrm{~mm})$ & 813,35 & $18,65 \%$ \\
$4(96 \mathrm{~mm})$ & 633,90 & $14,37 \%$ \\
\hline
\end{tabular}

economicamente desvantajoso ao produtor utilizar uma lâmina menor que $385 \mathrm{~mm}$. Esses resultados ilustraram, também, a influência que o custo total da irrigação representa na receita líquida, sendo que maiores lâminas resultaram em maiores receitas líquidas, porém requer um investimento inicial maior de capital. Observa-se, ainda, que, quanto maior for a lâmina, maior será a participação percentual da irrigação na receita líquida.

Na Figura 2 é apresentada a análise de sensibilidade relativa ao efeito da variação do custo da água sobre os valores de receitas líquidas para cada opção avaliada, mantendo-se fixo o preço do produto em $\mathrm{R} \$ 0,171 \mathrm{~kg}^{-1}$, e se observa, também, que a lâmina de $385 \mathrm{~mm}$ foi economicamente ótima para o custo da unidade de água, assumindo qualquer valor abaixo de $\mathrm{R} \$ 0,36$ para cada $10 \mathrm{~m}^{3}$; acima deste valor, a lâmina correspondente a $75 \%$ da lâmina máxima ( $289 \mathrm{~mm}$ ) foi a que proporcionou a maior receita líquida, ou seja, só é economicamente viável correr um risco de redução na produção, decorrente de veranicos, se a unidade de água tiver um custo superior a R $\$ 0,36$ para cada $10 \mathrm{~m}^{3}$. Para o custo da unidade de água acima de $\mathrm{R} \$ 1,00$ para cada $10 \mathrm{~m}^{3}$, a lâmina correspondente a $25 \%$ da lâmina máxima $(96 \mathrm{~mm})$ foi a que proporcionou os menores valores de receita líquida. Pode-se verificar, ainda, a pouca influência do custo da unidade de água na receita líquida, pois para um aumento no custo da água de $10.000 \%$, ocorreu redução de 38, 29, 22 e 14\% nas receitas líquidas para as lâminas relativas às opções 1, 2, 3 e 4 , respectivamente, cuja razão reside em ser o custo da água muito baixo. Nesse estudo, o custo da água reflete apenas os custos de bombeamento, já que não é cobrado o custo da utilização do recurso água, o que não favorece a adoção de práticas de manejo adequadas em projetos de irrigação.

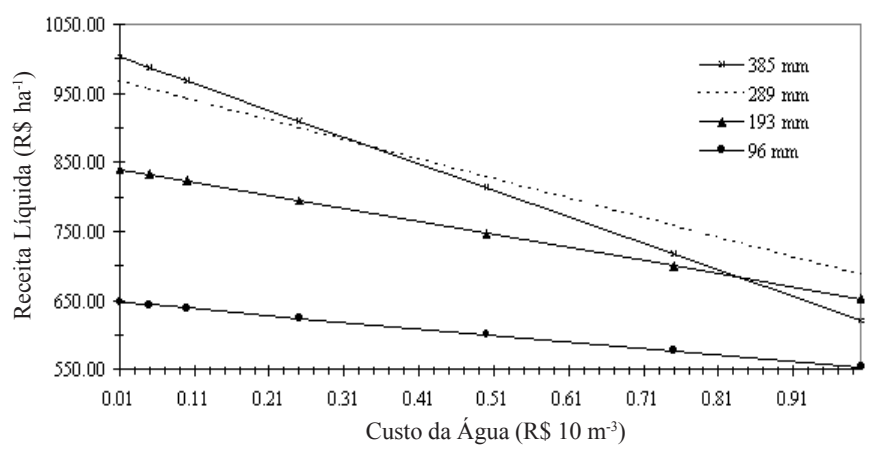

Figura 2. Análise de sensibilidade relativa às variações no preço da unidade de água em função da receita líquida 
Na Figura 3 tem-se a análise de sensibilidade para a variação do preço do produto sobre os valores das receitas líquidas para as diferentes lâminas de irrigação, mantendo-se fixo o preço da água, em $\mathrm{R} \$ 0,15$ para cada $10 \mathrm{~m}^{3}$. Observa-se que a receita líquida foi negativa, para o preço do milho inferior a $\mathrm{R} \$ 0,08 \mathrm{~kg}^{-1}$. Para um preço do produto superior a $\mathrm{R} \$ 0,13 \mathrm{~kg}^{-1}$, a lâmina de $385 \mathrm{~mm}$ foi a que proporcionou as maiores receitas líquidas, porém com pequena diferença para a lâmina de $289 \mathrm{~mm}$. O aumento do preço do produto favorece a utilização da maior lâmina de irrigação utilizada nesse estudo, sendo que o aumento do mesmo vai refletir em maiores diferenças entre as receitas líquidas obtidas para as lâminas correspondentes às opções $1 \mathrm{e} 2$. Com o aumento do preço do produto não é economicamente viável por haver deficiência e o custo da irrigação passa a ter menor influência na receita líquida.

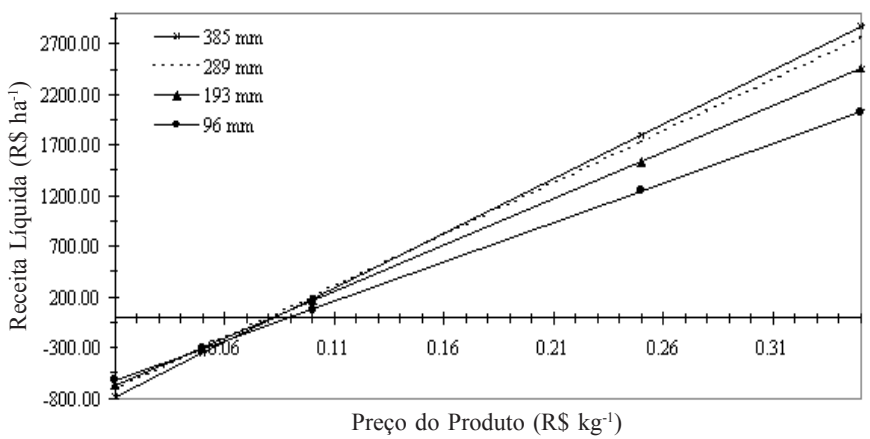

Figura 3. Análise de sensibilidade relativa às variações no preço do produto em função da receita líquida

\section{CONCLUSÕES}

Para a região de Sete Lagoas, os resultados permitiram concluir-se que:

1. A lâmina de irrigação correspondente à máxima produção física $(385 \mathrm{~mm})$ foi a que proporcionou a maior receita líquida para a cultura do milho doce.

2. Para o custo de água de até $\mathrm{R} \$ 0,36$ por $10 \mathrm{~m}^{3}$, a lâmina correspondente à máxima produção física foi a que proporcionou maior receita líquida. Acima deste valor, a maior receita líquida foi obtida com a aplicação de uma lâmina correspondente a $75 \%$ da máxima $(289 \mathrm{~mm})$.

3. A receita líquida foi negativa para o preço do milho doce até $\mathrm{R} \$ 0,08 \mathrm{~kg}^{-1}$, tornando-se positiva acima deste valor. Para o preço do milho superior a $\mathrm{R} \$ 0,13 \mathrm{~kg}^{-1}$, as maiores receitas líquidas foram obtidas para a lâmina de $385 \mathrm{~mm}$.

\section{LITERATURA CITADA}

Algozin, K.A.; Bralts, V.F.; Ritchie, J.T. Irrigation strategy selection based on crop yield, water, and energy use relationships: A Michigan example. Journal of Soil and Water Conservation, Ankeny, USA, p.428-31. 1988.

Bernardo, S. Manual de Irrigação. 5.ed. Viçosa: UFV, Imprensa Universitária, 1989. 596p.
Couto, L.; Costa, E.F.; Viana, R.T. Avaliação e comportamento de cultivares de milho em diferentes condições de umidade no solo. In: Resumo das atividades de pesquisa. Sete Lagoas: Centro-EMBRAPA, 1986. v.2, p.77-78.

Dantas Neto, J. Modelos de decisão para otimização do padrão de cultivo, em áreas irrigadas, baseados nas funções de resposta das culturas à água. Botucatu: UNESP, 1994. 125p. Tese Doutorado.

Doorenbos, J.; Kassam, A.H. Yield response to water. Rome: FAO, 1979. 193p. Irrigation and Drainage, Paper 33.

Doorenbos, J.; Pruitt, W.O. Crop water requirements. Rome: FAO, 1977. 144p. Irrigation and Drainage, Paper 24.

English, M.J.; Musick, J.T.; Murty, V.V.N. Deficit irrigation. In.: Glen, J.H.; Howel, T.A.; Salomon, K.H. (eds.) Management of farm irrigation systems. St. Joseph: ASAE Monograph, 1990. p.631-663.

Fancelli, A.L.; Dourado Neto, D. Milho: Fisiologia da produção. Seminário sobre fisiologia da produção e manejo de água e nutrientes na cultura do milho de alta produtividade. Potafos: Piracicaba, 1996.30p.

Klar, A.E. Freqüência e quantidade de aplicação. São Paulo: Nobel, 1991.156 p.

Marouelli, W.A.; Silva, W.L. de C. da; Silva, H.R. Manejo da irrigação em hortaliças. EMBRAPA-SPI: Brasília, 1994. 60p.

Moskowitz, H. Decision analysis In.: Ravidndran, A.; Phillips, D.T.; Solberg, J.J. (eds.) Operations research, principles and practice. New York: Hamilton Printing Company, 1986. p.237-259.

Nehmi, I.M.D.; Ferraz, J.V.; Nehmi Filho, V.A. Agrianual 96. Anuário estatístico da agricultura brasileira. São Paulo: Argos Comunicação, 1996. 481p.

Oliveira, S.L. de. Funções de resposta do milho doce ao uso de irrigação e nitrogênio. Viçosa: UFV, 1993.91p. Tese Doutorado

Priestley, C.H.B.; Taylor, R.J. On the assessment of surface heat flux and evaporation using large-scale parameters. Montly Weather Review, Washington, n.100, p.81-92, 1972.

Silva, D.D. da; Loureiro, B.T.; Bernardo, S.; Galvão, J.D. Efeitos de lâminas de água e doses de nitrogênio na cultura do milho irrigada por aspersão em linha. Revista Ceres, Viçosa, v.39, n.222, p.91-104, 1992.

Sousa, S.A.V.; Frizzone, J.A.; Peres, F.C. Otimização da irrigação para diferentes déficits nas lâminas de água aplicadas às culturas. In: Congresso Brasileiro de Engenharia Agrícola, 25, 1996, Bauru. Anais... Bauru: Sociedade Brasileira de Engenharia Agrícola, 1996. CD Rom.

Sousa, S.A.V.; Peres, F.C. Desenvolvimento de um programa computacional para simulação da ocorrência de veranicos e queda de produção. In: Congresso Brasileiro de Engenharia Agrícola, 25, 1996, Bauru. Anais... Bauru: Sociedade Brasileira de Engenharia Agrícola, 1996. CD Rom.

Zocoler, J.L. Custos da irrigação por aspersão convencional em função da pressão de operação, diâmetro dos bocais e espaçamento dos aspersores. Piracicaba: ESALQ/USP, 1994. 120p. Dissertação Mestrado 